\title{
Inequalities in exposure and awareness of flood risk in England and Wales
}

Jane L. Fielding, Senior lecturer in quantitative methods, Department of Sociology, University of Surrey, United Kingdom

This paper explores the environmental inequalities of living in the floodplains of England and Wales and the differences in flood awareness of those 'at risk'. An area comparison is made between an etic, objective flood risk exposure, and an emic, subjective perception of that risk by social class. In all areas except the Midlands, the working classes were more likely to reside in the floodplains; the greatest exposure inequality is seen in the North East and Anglian regions. Flood awareness in the Anglian regions was much lower than average, but there were no significant class differences. In the Thames region, despite equal flood risk exposure between classes, the most deprived displayed the least awareness of flood risk. In the North East, inequalities in the distribution of flood risk exposure accompanied inequalities in perception, resulting in the least aware and most deprived experiencing the greatest flood risk.

Keywords: flood awareness, flood risk, environmental justice, inequalities

\section{[A] Introduction}

Flood risk is an issue of increasing concern in the United Kingdom, especially since the devastating floods of 2007, which prompted the commission of Sir Robert Pitt to conduct a review of events before, during, and after the floods (Pitt, 2008). In England and Wales alone, some five million people and two million properties are identified as being in areas that are at risk of flooding (EA,n.d.a). With the claim that the number of people at 'high' risk from flooding in the UK could rise from 1.5 million to 3.5 million between 2030 and 2100 (Foresight, 2004), the potential scale of social and economic disruption becomes all too clear. The problem is of considerable concern to the UK Environment Agency (EA), which, since the severe flood events of 1998, 2000, and 2007, has placed a high priority on the need to increase public awareness with regard to flood risk. The Pitt Review makes a pertinent recommendation:

The Environment Agency should work with local responders to raise awareness in flood risk areas and identify a range of mechanisms to warn the public, particularly the vulnerable, in response to flooding (Pitt, 2008, p. xxxi).

The issues of who is at risk and whether there are inequalities in the distribution of flood risk are also of concern. This is the arena of environmental justice and social equality. Interest in environmental justice originated in the United States in the 1980s and mainly revolved around the co-location of waste sites and heavy industry in areas predominantly populated by ethnic minorities. Environmental justice has been defined by the US Environmental Protection Agency as the:

fair treatment and meaningful involvement of all people regardless of colour, race, national origin or income with respect to the development, implementation, and enforcement of environmental laws, regulations and policies (EPA, n.d.).

In the UK, the issue of environmental justice is also now high on the agenda of policy-makers and funding agencies (EA, 2001; ESRC, 2001). 
While the original concern was for those living in close proximity to polluting factories and other installations, unequal risks to the population have now extended to include all kinds of environmental threats, including natural risks, such as those presented by floods and earthquakes (Buckle et al., 2000; Enarson and Fordham, 2001; Wisner et al., 2004).

Recent research for the UK Environment Agency finds no disproportionate distribution of the population in the lower (more deprived) deciles residing within the fluvial floodplain of England, although there did seem to be a relationship between more deprived ward populations and flood hazard in tidal floodplains (Walker et al., 2003). Walker et al. (2006) extend this work using the more recent EA 2004 flood maps, deprivation deciles derived from the UK 2004 Index of Multiple Deprivation data (IMD2004) (National Archives n.d.) and aggregated to super output areas (SOAs) (with populations around 1,500), and the Ordnance Survey's Address-Point ${ }^{\circledR}$ to capture at-risk addresses within each SOA. The Ordnance survey is the national mapping agency of Great Britain and Address Point is the mapping product which is used to locate all residential and other addresses. Yet Walker et al. acknowledge that a limitation of this method is that 'all addresses within a SOA are still necessarily assumed to have the same deprivation characteristics' (Walker et al., 2006, p. 52). Once again, they reveal that inequality existed within the tidal floodplains in all regions within England and Wales, but they find no overall inequality within the fluvial floodplains despite great regional variation in inequalities.

To explore different measures of inequality within the floodplains and to try to address the problem of aggregating deprivation profiles to large areas such as wards and the SOAs, Fielding and Burningham (2005) employ a spatial method that redistributes population characteristics-derived from the UK 1991 Census data-as population grids using Surface Builder, a freely available programme, developed by David Martin (Martin \& Brackan 1999, Surface Builder (n.d.)) These spatially distributed populations, characterized by social class, were then 'captured' using spatial techniques in GIS software and defined as 'at risk' if they resided within the extent of the EA indicative flood map. The research finds that overall, the lower social classes and the unemployed experienced a greater flood risk (Fielding and Burningham, 2005); however, no distinction was made between tidal and fluvial risk.

This research was then extended using the 2004 EA flood maps and the 2001 Census; a distinction was made between the fluvial and tidal flood risk (Fielding, 2007). Using surface population models and logistic regression analysis, Fielding shows that a significant inequality existed between the middle and working classes, and also between the middle classes and the inactive (the unemployed and unclassifiable classes, not the retired) in risk factors associated with flood emergencies in all EA regions of England and Wales except the Midlands region. The research demonstrates that, overall, inequality is reproduced in both the fluvial and tidal floodplains, although it is more significant and pronounced in the latter, especially in the eastern regions of England.

So it is clear that there are inequalities in the distribution of flood risk in the UK; whether those inequalities have arisen because those communities are disadvantaged or in spite of their disadvantage remains debatable. Talih and Fricker (2002) determine that there are two approaches to studying environmental justice. The first determines whether there is an association between distinguishing demographics and the location of environmentally undesirable sites (an outcome-based approach) and the second examines how such associations may have occurred (a process-based approach). Therefore, they maintain that the existence of environmental inequality does not necessarily imply that any overt discrimination has occurred because of their disadvantage, but in spite of their disadvantage.

In other words, association is not enough to discern any positive discrimination; evidence of that would be the conclusion of a causal analysis. However, this is not to say that this association is not inequitable. Indeed, many studies show that the poor, the disabled, the 
young, women, the very old, and other groups are less able to cope-whether physically, financially, or psychologically-in extreme situations, such as during or following a flood (Cutter, 2003; Cutter et al., 2003; Cutter and Emrich, 2006; Fordham, 1998; 1999; Tapsell et al., 2002; Wisner et al., 2004). For a review of the extensive literature on the link between poverty and disasters, see Fothergill and Peek (2004) or Cutter et al. (2009).

In the short term, poorer people may be less likely to have sufficient available financial resources to cover them during an emergency; they are also often less able to carry on with their jobs if they are temporarily displaced from their homes. In addition, poorer people are less likely to be insured and therefore less likely to be able to recover all their lost assets or rebuild their damaged homes, especially given the consequent physical and psychological stresses involved (Enarson and Fordham, 2001). Even at the community level, this disadvantage is felt where poorer communities are less likely to have the political voice to engage in community reconstruction. The adverse impacts of flooding are thus disproportionately felt even long after the original disaster event.

Further afield, especially in less developed countries, research has amply shown that the most vulnerable in society are more likely to live in the most risky areas, often because these areas are less desirable and therefore cheaper places to live (Wisner et al., 2004). Not only do the most vulnerable often live at higher risk, but they are also the least resilient and have the least adaptive capacity; they are often unable, because of their circumstances, to 'learn' from their experience.

Another category of vulnerable people comprises those who are newly settled or who just moved to an at-risk area. These populations range from tourists to migrants (both internal and external) who are particularly vulnerable due to a lack of local knowledge, resources, or language skills. In addition, climate change is now generally predicted to contribute to future flood risk (UKCIP, 2009; Milly et al., 2002); specifically, there is evidence that climate change will have an impact on migration patterns (Hugo, 1996; Raleigh et al., 2008). While much of this research has explored the potential movements of 'distress migrants' escaping from local flood risk areas, mainly in the developing world, there is also the potential that such 'climate migrants' will migrate more widely to areas with less risk. In 2009 Professor John Beddington, the UK government's chief scientific adviser, commented that climate change may trigger a wave of migration to cooler climates, such as the UK (Leake, 2009).

This paper sets out to explore the distribution of risk within an outcome-based framework within England and Wales. It does not seek to examine the origins of that risk-why or by what course of historical events the disadvantaged have come to be disproportionately at risk. That goal would require a more longitudinal, process-based approach, which is beyond the scope of the current analysis. However, this paper does seek to relate the relationship between inequalities in the distribution of flood risk and the capacity of those most at risk to cope with that risk, namely their resilience. One aspect of this resilience is whether they are aware of their risk.

A useful framework for exploring these ideas is that of etic and emic conceptualization of vulnerability (Spiers, 2000; Fielding et al., 2005). These concepts, reinterpreted from linguistics and anthropology, refer to two complementary perspectives.

An etic viewpoint defines vulnerable individuals as those at greater risk based either on where they live (in vulnerable places, such as floodplains) or on demographic characteristics (vulnerable people). These characteristics are usually seen as contributing to social dependence; they include old age, ill health, disability, poverty, and ethnicity (in terms of language barriers). Quantitative methods are nearly always used to identify vulnerable places (measuring the likelihood of an event occurring) and are also often used to identify vulnerable people. One negative consequence of this approach is that individuals may 
become stereotyped based on the defining functional deficit. Another problem is that such defined 'vulnerable groups' are not homogenous.

In contrast, an emic viewpoint - which tends to be aligned with qualitative methodologyseeks to identify vulnerability on the basis of meanings held by individuals, usually arising from their lived experience. Emic vulnerability is founded on a person's, family's, or community's sense of their own resilience and ability to respond in the face of a flood. In terms of flood risk, emic vulnerability can only be determined by the person experiencing it. People who may be defined as belonging to an at-risk group (etic vulnerability) may only feel vulnerable if they consider some threat to their person to exceed their capacity to adequately respond, despite 'rationally' acknowledging their possession of vulnerable characteristics. They need to recognize that they are at risk before they can effectively prepare. Thus, while awareness of risk may not lead to an appropriate action, it could be argued that unless someone admits to being aware of their risk status and feels threatened (that is, feels vulnerable), he or she is unlikely to take appropriate action. Much in the same way, for smokers to give up cigarettes, they must consciously recognize they are at risk-trusting the message that there is some threat to their health - to have the capacity to respond to the threat, by giving up smoking.

\section{[B] Etic perspectives on flood risk: risky places and risky people}

From an etic perspective, vulnerable populations (risky people) are defined as those who live within the floodplains (risky places), such as those defined by the flood maps developed by the EA. The 'at risk' database of postal addresses was created by the EA to target flood risk populations, often by a postal mail-out, but also to be able to aim their awareness campaigns at populated flood-prone regions. Generally carried out annually, these awareness campaigns are designed to educate the vulnerable public about flood facts.

\section{[B] Emic perspectives on flood risk: public awareness of risk}

The emic perspective aims to ascertain whether the 'at-risk' public as defined above felt at risk or were aware of their risk. It is apparent that the EA campaign messages were not getting through. In 2009, the EA reported that 40 per cent of all at-risk populations in 2009 were not aware that their property was in a flood-risk area (EA, n.d.b). Thus, while the quantitative measurement of the extent of the floodplains had been used to identify the 'atrisk' population, another quantitative analysis identified a differing perception of reality of those living within those areas. The imposed, outsider view that defined risky places was at odds with the lived experience of those defined 'at risk'.

Why were those who are vulnerable according to etic measures not aware of their risk? Previous research has shown that there is a clear social class gradient in awareness; the lower social classes, the very young, and the very old - in other words, those with the highest financial or social dependency_are least aware of their flood risk (Fielding et al., 2007; Burningham et al., 2008). However, a lack of awareness on its own, measured quantitatively, does not necessarily reveal the complete picture, as underlined by the following quote from the Pitt Review:

The public need to be aware of a flooding risk before they can take action to minimise it. But even being aware of risk may not be enough_of those we talked to who actually knew prior to the floods that they were at risk, relatively few had done anything to prepare (Pitt, 2008, p. xxxi). 
Being aware is thus the first step in being prepared; yet for people to recognize their risk and take appropriate action, other factors come into play, not least their trust in the messenger and their belief in their ability to cope in the face of impending danger.

Green et al., (1991) show that people's expectations of their flood risk is based on their past experience, which often leads them to underestimate the impact of rare and exceptional flood events. Similarly, Burningham et al., (2008) conclude that people evaluate their risk based on past experience and that their apparent lack of awareness may be accounted for by their local knowledge and their belief that 'it will never happen to me'. They also find that people may acknowledge their lack of awareness but either be unconcerned or in denial of their risk while placing blame on their lack of trust in the providers of information. The invisibility of flood risk is also seen as a factor in people's response-because you can't see it, it doesn't exist. Another factor is that acknowledgement of flood risk is perhaps an acknowledgement of the devaluation of a home, recognition that perhaps the home may be uninsurable or even unsellable.

Depending on personal circumstances, recognition of vulnerability to flood risk according to the etic flood maps may either be accepted and acted upon-a situation where the emic and etic perspectives coincide-or rejected, with the etic and emic viewpoints at variance. In the latter case, there are two possibilities. First, the respondent is not actually at risk-due either to an error in the flood maps (the respondent lives on an isolated hill or recent flood defences have not been taken into account) or personal circumstance (the respondent lives above the ground floor). Second, the respondent is at risk (according to the map) but does not perceive this risk to be significant. Research has shown that inequalities between classes exist in the distribution of flood risk in the fluvial and tidal floodplains in England and Wales, and that, in addition, there are class differences in flood awareness.

This study aims to explore the correlation between inequalities in hazard exposure and the variance of awareness in different regions of England and Wales. It updates the current literature in the light of recent flood events, specifically following the 2007 flood events in England and Wales.

\section{[A] Methodology}

\section{[B] Measuring the emic perspective: perceptions of flood risk}

Ipsos MORI investigated flood awareness for the Environment Agency using a secondary analysis of data collected in 2007-8 (Ipsos MORI, 2008). This survey was conducted in March 2008 with a view to evaluating the effectiveness of the flood awareness campaigns run during 2007-8. The data was weighted by region and severity of flood risk. The final weighted sample was representative not only by the proportions at risk in each region, but also by their level of risk. The survey asked: 'Is your property at risk of flooding? Would you say it is ...?' Respondents could select one of the following responses: 'Definitely at risk', 'Possibly at risk' (both recoded to indicate 'aware'), or 'Not at all at risk' (recoded to indicate 'not aware').

\section{[B] Measuring the etic perspective: identification of risky areas}

Respondents were defined as 'at risk' from tidal or fluvial flooding although they may never have actually experienced a flood event. The 'at risk' samples were identified by the use of floodplain maps. It may seem obvious that residents within the floodplains are most at risk from flooding and comprise the 'at-risk' population, yet measuring the extent of the 
floodplains and quantifying the likelihood of floods is a contentious exercise complicated by many factors, ranging from climate change to the involvement of the insurance industry.

Areas at risk were those defined by the Environment Agency as those within the Zone 2 floodplains. Floodplain maps, based on annual risk, apply the following categories:

- Zone 1: those with little or no risk (chance of any flooding <1 in 1,000-year period);

- Zone 2: those with low to medium risk (chance of any flooding from rivers or the sea $>1$ in a 1,000-year period); and

- Zone 3: those living in high-risk areas (chance of any flooding $>1$ in a 100-year period or chance of sea flooding $>1$ in a 200 -year period).

Zone 2 flood areas represent the extent of an extreme flood event. Note that those living within Zone 2 also include those living within Zone 3. This research compares those in Zone 1 , who are considered at minimal flood risk, with those in Zone 2, who are considered at risk from flooding. All the results are based on comparisons across the eight EA regions, which are broadly defined by the major river catchment areas in England and Wales.

Regional analysis was considered an appropriate strategy in the light of the regional variation in the impact of the 2007 floods. In researching the cost of the summer floods of 2007 in England for the Environment Agency, Chatterton et al. (2010) find that some regions were particularly hard hit, as measured by the count and damage costs of insurance claims following the floods. Those areas included South and East Yorkshire, Worcestershire, Gloucestershire, and Oxfordshire; they are shaded on the Environment Agency regional boundaries in Figure 1. In addition, regional comparisons are considered important since the predicted increased flood risk due to climate change is also forecast to be differentially felt throughout the British Isles (UKCIP, 2009). This differential effect will arise due to the independent tilting of the north-west/south-east longitudinal axis of the British Isles, which would see those areas in the South East suffering an increased flood risk as the axis tilts (ODPM, 2004).

Figure 1 Environment Agency regions and the impact of the 2007 floods 


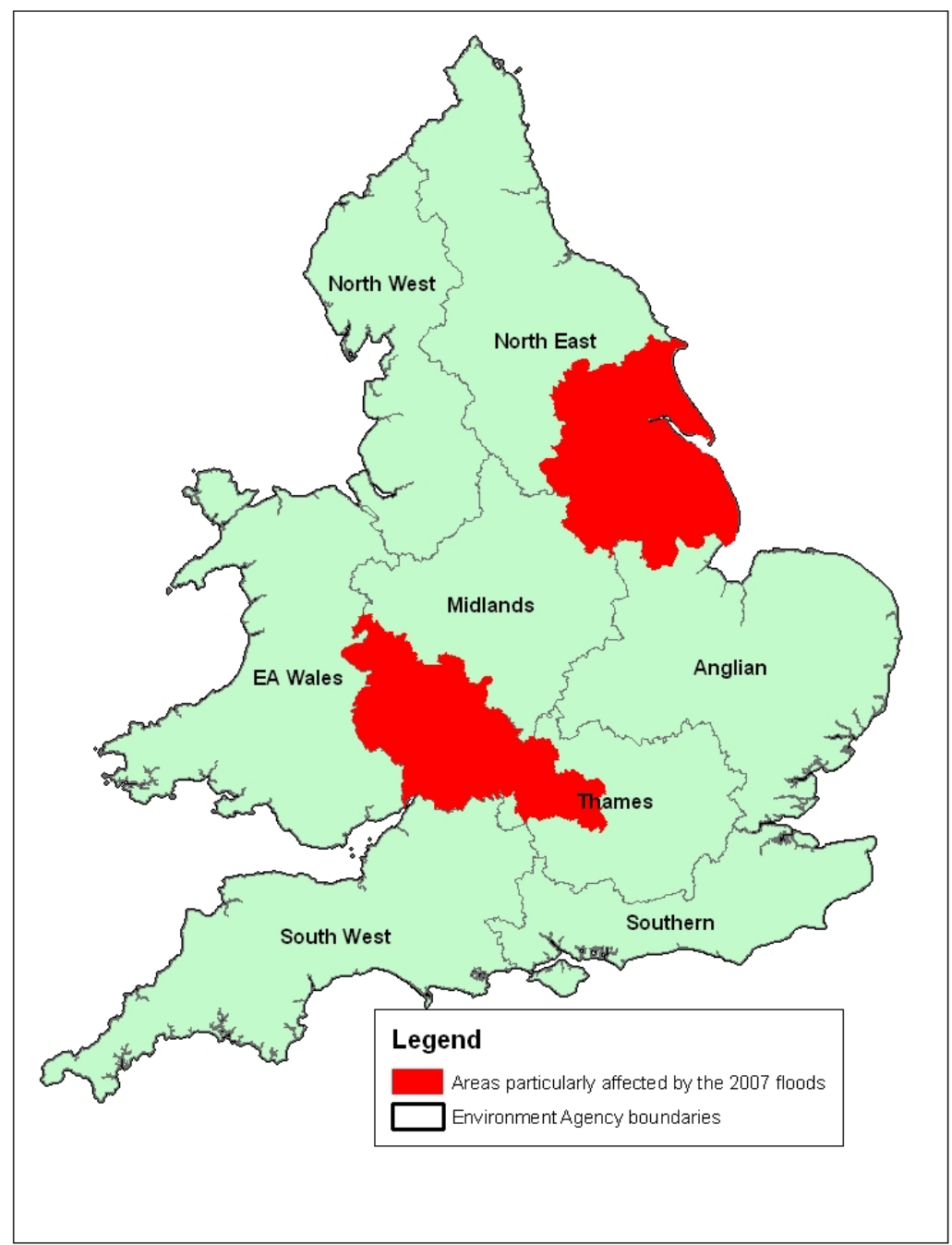

Sources: Chatterton et al. (2010)

\section{[B] Measuring the etic perspective: identification and characteristics of 'at-risk' populations}

The EA maps identify the 'risky places' but are also used to pinpoint the 'at-risk' populations living within them.

This paper uses social class as an indicator of social standing within society and, potentially, a measure of dependency or vulnerability within a community. While the conceptualization of social class as an indicator of poverty or social deprivation may be contended, it is commonly used to investigate health inequalities (Scambler and Higgs, 2001; Chandola, 2000). In quantitative studies of inequality, measures of social division or difference are often defined by available data; this study takes a similar approach. Using categorized class indicators (such as that available in the 2001 UK Census) to measure economic difference departs from some more recent cultural approaches to class analysis, which theorize class as individualized hierarchies (Devine and Savage, 2000; Bottero, 2004); nevertheless, such analysis has value in identifying quantifiable difference, especially at the household level. 


\section{[B] Social class in the 2001 census}

The social class variable-NS-SEC- - used in the 2001 UK Census was developed from the 'Goldthorpe Schema' (Erikson and Goldthorpe, 1992), an internationally recognized predictor of health and educational outcomes (Marshall et al., 1997). It was designed to measure social relationships in the workplace based on employment relations. Such employment relations relate to income, economic prospects, and job security. Further validation of the use of this social class classification, especially of the long-term unemployed (as a separate category) and of the retired (by their last main occupation), can be found in Rose et al (1997).

This analysis focuses on households at risk from flooding, and therefore a household measure of social class is most appropriate. It is measured by the class of the household reference person (HRP), defined as the member of the household in whose name the accommodation is owned or rented. If the household is jointly owned or rented, the member with the highest income is the HRP. This is an example of the 'dominance' approach to measuring class (Erikson, 1984).

Area statistics for social class were downloaded from the 2001 Census via Casweb, from Table CAS044, 'NS-SEC of Household Reference Persons (HRP) aged 16-74 in England and Wales' (CDU, n.d.). The data, with spatial referents, were then entered into SPSS for preliminary recoding of social class (NS-SEC); it was subsequently entered (as csv format files) into Surface Builder to create six separate social class grids. For the purpose of comparison and a clearer analysis, these six classes were recoded into three groups: middle class, working class, and inactive (see Table 1).

Table 1 Social class groupings

\begin{tabular}{|l|ll|}
\hline \multirow{4}{*}{ Middle class } & 1. & Higher and lower managerial and professional \\
\cline { 2 - 3 } & 2. & Intermediate occupations \\
\cline { 2 - 3 } & 3. & Small employers and own account workers \\
\hline Working class & 4. & Lower supervisory and technical occupations \\
\cline { 2 - 3 } & 5. & Semi-routine and routine occupations \\
\hline Inactive & 6. & Never worked and long-term unemployed/unclassified \\
\hline
\end{tabular}

Surface Builder, developed by David Martin (Martin and Bracken, 1999), imputes the distribution of larger area statistics (in this case, output areas) into 200-metre grid squares based on the population centroids for each area (Martin, 1989; Bracken and Martin, 1989; Surface Builder , n.d.). These surface population grids are then imported into ArcView for analysis. For a full description of this methodology, see Fielding and Burningham (2005) and Fielding (2007).

\section{[A] Results and discussion}

\section{[B] Estimation of etic risk}

An initial analysis of populations 'at risk' showed that the Thames region (14 per cent), followed by Anglian region (13 per cent), had the highest proportion of their populations within the Zone 2 floodplains (see Figure 2). The Midlands region was least at flood risk (7 per cent). This study does not explore whether these area risk differences have arisen due to any direct discrimination — such as a greater amount of building on the floodplains — or 
whether they are just more heavily populated and therefore have a greater likelihood of risk; this topic could be the subject of further research. The question of interest here is whether there were class inequalities within these EA regions.

Figure 2 Proportion of households within the Zone 2 floodplains, by region

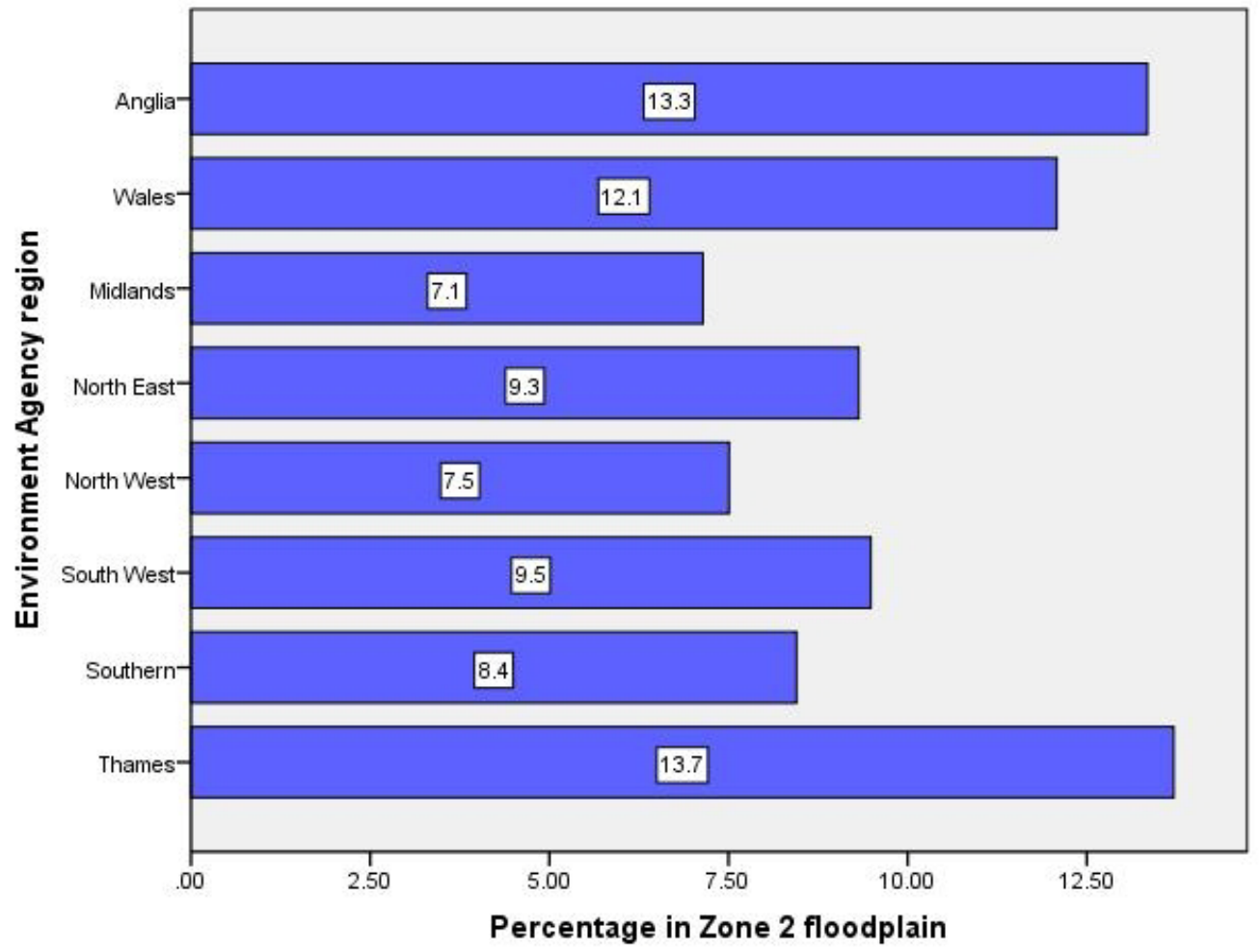

Source: author's analysis of 2001 Census (ONS, 2001)

\section{[B] Flood risk and class}

Research has shown that class inequalities exist in all EA areas except the Midlands region with regard to overall flood risk (Fielding, 2007). The working classes are more likely to reside in the floodplains than the middle classes (see Table 2). 
Table 2 Proportion in Zone 2 floodplains, by region and class

\begin{tabular}{|l|r|r|r|r|r|}
\hline \multirow{2}{*}{ Region } & \multirow{2}{*}{ No. of households } & \multicolumn{3}{|l|}{ Percentage of class within Zone 2 floodplains } \\
\cline { 3 - 6 } & & Middle class & Working class & Inactive & \multicolumn{1}{l|}{ Total } \\
\hline 1. Anglia & $2,090,562$ & $11.7 \%$ & $15.2 \%$ & $14.7 \%$ & $13.3 \%$ \\
\hline 2. Wales & $1,135,195$ & $11.4 \%$ & $12.7 \%$ & $12.4 \%$ & $12.1 \%$ \\
\hline 3. Midlands & $3,090,295$ & $7.3 \%$ & $7.1 \%$ & $6.9 \%$ & $7.1 \%$ \\
\hline 4. North East & $2,629,608$ & $8.4 \%$ & $10.3 \%$ & $9.4 \%$ & $9.3 \%$ \\
\hline 5. North West & $2,470,377$ & $7.3 \%$ & $7.8 \%$ & $7.6 \%$ & $7.5 \%$ \\
\hline 6. South West & $1,513,869$ & $9.2 \%$ & $10.1 \%$ & $9.3 \%$ & $9.5 \%$ \\
\hline 7. Southern & $1,657,054$ & $7.9 \%$ & $9.3 \%$ & $8.8 \%$ & $8.4 \%$ \\
\hline 8. Thames & $4,444,968$ & $13.3 \%$ & $13.9 \%$ & $14.6 \%$ & $13.7 \%$ \\
\hline Percentage overall in floodplains & $10.1 \%$ & $10.6 \%$ & $10.5 \%$ & $10.3 \%$ \\
\hline \multicolumn{2}{|l}{ Total households in floodplains } & 920,805 & 557,400 & 482,379 & $1,960,584$ \\
\hline
\end{tabular}

Source: author’s analysis of 2001 Census (ONS, 2001)

Following a logistic analysis, a comparison of the odds ratios of being middle class vs. being either working class or inactive and being at flood risk showed that inequality was greatest in the Anglian and North East regions. The working classes in these regions were 35 per cent and 25 per cent more likely, respectively, to reside in the Zone 2 floodplains than the middle classes in those regions.

\section{[B] Estimating the emic risk}

These results are to be contrasted with an analysis obtained using Ipsos MORI's 'at risk' survey conducted for the EA in 2007-8. Figure 3 demonstrates that in 2008, the most floodaware residents lived in the Southern (62 per cent aware) and the Thames (59 per cent) regions, followed by those in the North East (58 per cent). However, the average, overall residential awareness applies to just over half the at-risk population (55 per cent); the lowest awareness levels are seen in the Anglian (45 per cent) and Midlands (48 per cent) regions.

Figure 3 Flood risk awareness in 2007-8, by region 


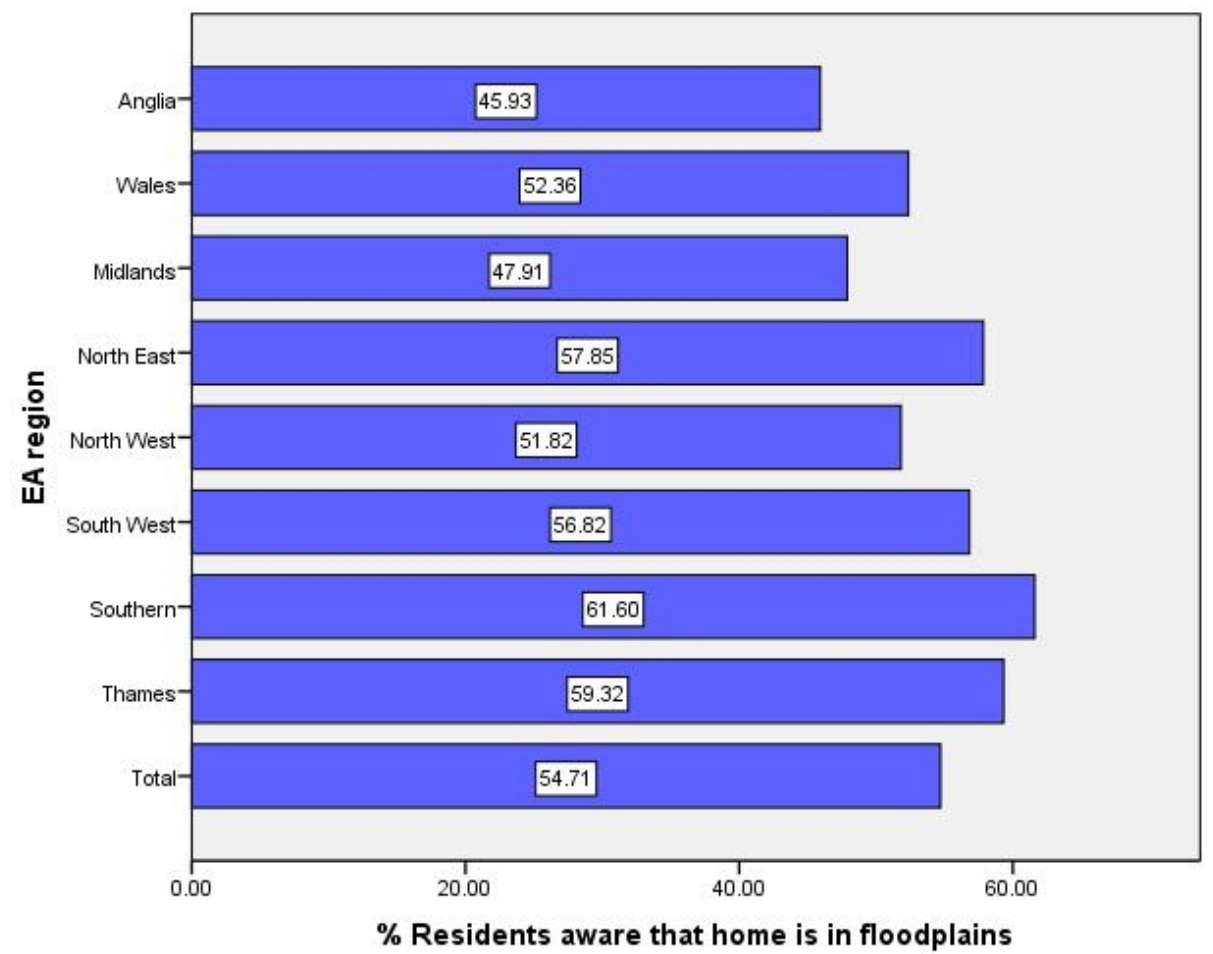

Source: author's analysis of Ipsos MORI (2008)

\section{[B] Awareness and social class}

An examination of class inequalities within regions reveals that, despite differing levels of flood risk, most regions showed no significant class differences (see Table 3). The two exceptions were the North East and the Thames regions. In the North East, where the working classes are significantly less likely than the middle classes to be risk-aware, the inactive are significantly more likely to be aware. In the Thames region, the middle classes are significantly more likely to be aware of risk but the inactive are more likely to be aware than the working classes. Since the base numbers of the inactive in some regions are very low, this category will not be used in further analysis in this paper.

\section{Table 3 Percentage of at-risk residents aware of flood risk, by region and class}

\begin{tabular}{|c|c|c|c|c|c|c|c|}
\hline \multirow[t]{2}{*}{ Region } & \multirow{2}{*}{$\begin{array}{l}\text { No. of } \\
\text { respondents }\end{array}$} & \multicolumn{4}{|c|}{ Percentage of 'at risk' residents aware of flood risk } & \multirow[t]{2}{*}{ Significance } & \multirow{2}{*}{$\begin{array}{l}\text { \% respondents } \\
\text { flooded in } 2007\end{array}$} \\
\hline & & Middle class & Working class & Inactive & Total & & \\
\hline 1. Anglia & 159 & $46.4 \%$ & $47.1 \%$ & $37.5 \%$ & $45.9 \%$ & & $1.2 \%$ \\
\hline 2. Wales & 73 & $55.9 \%$ & $48.4 \%$ & $50.0 \%$ & $52.1 \%$ & & $0.0 \%$ \\
\hline 3. Midlands & 97 & $61.1 \%$ & $48.0 \%$ & $37.9 \%$ & $47.4 \%$ & & $7.6 \%$ \\
\hline 4. North East & 151 & $63.3 \%$ & $46.3 \%$ & $75.0 \%$ & $57.6 \%$ & $*$ & $11.0 \%$ \\
\hline 5. North West & 102 & $57.5 \%$ & $46.0 \%$ & $58.3 \%$ & $52.0 \%$ & & $0.0 \%$ \\
\hline 6. South West & 76 & $56.8 \%$ & $58.3 \%$ & $50.0 \%$ & $56.6 \%$ & & $0.0 \%$ \\
\hline 7. Southern & 79 & $55.8 \%$ & $65.5 \%$ & $85.7 \%$ & $62.0 \%$ & & $0.0 \%$ \\
\hline 8. Thames & 255 & $68.4 \%$ & $39.7 \%$ & $51.4 \%$ & $59.3 \%$ & $* *$ & $2.0 \%$ \\
\hline \multicolumn{2}{|c|}{ Percentage aware } & $61.0 \%$ & $47.7 \%$ & $53.2 \%$ & $54.6 \%$ & $* *$ & $3.1 \%$ \\
\hline \multicolumn{2}{|c|}{ Total respondents } & 482 & 411 & 141 & 1,034 & & \\
\hline
\end{tabular}


Notes: Chi-square significance: ${ }^{*} \mathrm{p}<0.01 ; * * \mathrm{p}<0.001$.

Source: author's analysis of Ipsos MORI (2008)

It is worth noting that all residents who were flooded in 2007 in their current residence were aware of their flood risk. However, of those who were not flooded, the class differences seen in the North East and in the Thames regions remain the only significant differences.

Overall, 77 per cent of those with previous flood experience in their current residence (19 per cent of the sample) were aware of their risk, compared to 49 per cent of those with no previous flood experience. Regional differences still prevail. As Table 4 shows, perhaps surprisingly, there are no significant differences between those with and without experiences in their claimed awareness of flood risk in the South West, Wales, or Anglia. It is interesting that these are areas where awareness is generally lower than in other regions. Yet previous experience has a significant impact on awareness in all other regions. Three of these regions - the Midlands, the North East, and the Thames regions - were particularly hard hit in the mid-2007 floods, which might account for some of this difference in awareness.

\section{Table 4 Regional differences in awareness and previous flood experience}

\begin{tabular}{|c|c|c|c|c|c|}
\hline \multirow[t]{2}{*}{ Region } & \multicolumn{2}{|c|}{ Percentage aware of flood risk } & \multirow[t]{2}{*}{ Significance } & \multicolumn{2}{|c|}{$\begin{array}{l}\text { Respondents with previous } \\
\text { experience }\end{array}$} \\
\hline & $\begin{array}{l}\text { Previous flood } \\
\text { experience }\end{array}$ & No previous experience & & $\begin{array}{l}\text { No. of } \\
\text { respondents }\end{array}$ & Percentage \\
\hline 1. Anglia & $47.10 \%$ & $45.20 \%$ & & 171 & $19.90 \%$ \\
\hline 2. Wales & $50.00 \%$ & $53.30 \%$ & & 78 & $15.40 \%$ \\
\hline $\begin{array}{l}3 . \\
\text { Midlands }\end{array}$ & $94.70 \%$ & $34.20 \%$ & $* * *$ & 99 & $19.20 \%$ \\
\hline $\begin{array}{l}\text { 4. North } \\
\text { East }\end{array}$ & $91.30 \%$ & $51.20 \%$ & $* * *$ & 152 & $15.10 \%$ \\
\hline $\begin{array}{l}\text { 5. North } \\
\text { West }\end{array}$ & $92.30 \%$ & $38.60 \%$ & $* * *$ & 100 & $26.00 \%$ \\
\hline $\begin{array}{l}\text { 6. South } \\
\text { West }\end{array}$ & $72.70 \%$ & $53.10 \%$ & & 79 & $13.90 \%$ \\
\hline $\begin{array}{l}7 . \\
\text { Southern }\end{array}$ & $88.20 \%$ & $54.30 \%$ & $*$ & 63 & $27.00 \%$ \\
\hline $\begin{array}{l}8 . \\
\text { Thames }\end{array}$ & $78.80 \%$ & $55.50 \%$ & $* *$ & 295 & $17.30 \%$ \\
\hline Overall & $\begin{array}{r}76.80 \% \\
\text { (193 respondents) }\end{array}$ & $\begin{array}{r}49.30 \% \\
\text { (844 respondents) }\end{array}$ & $* * *$ & 1,037 & $18.60 \%$ \\
\hline
\end{tabular}

Notes: Chi-square significance: ${ }^{*} \mathrm{p}<0.05 ; * * \mathrm{p}<0.01 ; * * * \mathrm{p}<0.001$.

Source: author's analysis of Ipsos MORI (2008)

In an attempt to disentangle the impacts of region, class, and risk experience on awareness, a multivariate logistic regression analysis was conducted to predict awareness of risk.

Because of low base numbers, comparisons are only made between the middle classes and the working classes. The focus is on class effects within each region compared to all other regions (see Table 5). In each region, the middle classes are the reference category (with an odds ratio of 1.0) and are compared to the other two groups - the working classes in that region and all classes in all other regions. 
Table 5 Logistic regression predicting awareness of flood risk, showing odds ratios for class effects within region and the effects of previous flood experience

\begin{tabular}{|c|c|c|}
\hline & Model 1 & Model 2 \\
\hline Thames middle class (REF) & 1.0 & 1.0 \\
\hline Thames working class & $0.30 * * *$ & $0.32 * * *$ \\
\hline Compared to all other regions & 0.807 & 0.793 \\
\hline Anglia middle class (REF) & 1.0 & 1.0 \\
\hline Anglia working class & 1.04 & 0.75 \\
\hline Compared to all other regions & 2.075 & 1.847 \\
\hline Wales middle class (REF) & 1.0 & 1.0 \\
\hline Wales working class & 0.74 & 0.78 \\
\hline Compared to all other regions & 1.406 & 1.418 \\
\hline Midlands middle class (REF) & 1.0 & 1.0 \\
\hline Midlands working class & 0.62 & 0.66 \\
\hline Compared to all other regions & 1.176 & 1.308 \\
\hline North East middle class (REF) & 1.0 & 1.0 \\
\hline North East working class & $0.48 *$ & 0.55 \\
\hline Compared to all other regions & 1.012 & 1.029 \\
\hline North West middle class (REF) & 1.0 & 1.0 \\
\hline North West working class & 0.68 & 0.77 \\
\hline Compared to all other regions & 1.348 & 1.611 \\
\hline South West middle class (REF) & 1.0 & 1.0 \\
\hline South West working class & 0.97 & 0.95 \\
\hline Compared to all other regions & 1.298 & 1.220 \\
\hline Southern middle class (REF) & 1.0 & 1.0 \\
\hline Southern working class & 0.86 & 0.67 \\
\hline Compared to all other regions & 1.240 & 1.261 \\
\hline \multicolumn{3}{|l|}{ Previous flood experience } \\
\hline No (REF) & & 1.0 \\
\hline Yes & & $3.71 * * *$ \\
\hline Chi-square significance of model & $* *$ & $* * *$ \\
\hline
\end{tabular}

Notes: Chi-square significance: * $\mathrm{p}<0.05$; ${ }^{* *} \mathrm{p}<0.01$; ${ }^{* * *} \mathrm{p}<0.001$; REF: reference category. Source: author's analysis of Ipsos MORI (2008)

Model 1 reveals significant class differences in the Thames and the North East regions, where the working classes are less aware of their risk (70 per cent less aware in the Thames region and 52 per cent less aware in the North East). However, Model 1 also shows that in a comparison of middle class awareness in each region with overall awareness in all other regions, there are no significant differences.

Model 2 introduces previous awareness as a control and reveals that while the significant differences in the Thames region remain, those in the North East disappear, suggesting that in this region the class differences previously seen were partly due to differences in previous flood experience. Model 2 shows clearly that previous experience has the greatest impact on awareness; those with experience are nearly four times more likely to be aware of their risk than those without previous flood experience.

\section{[B] Flood risk and risk awareness: comparing the emic and the etic}

It has thus been established that there are class and regional inequalities in hazard exposure and, in addition, class and regional differences in flood awareness. The question posed by the 
following analysis is whether these inequalities coincide-are there any regions or classes that suffer a double jeopardy? These two sets of results were explored together to establish which areas display high risk/high awareness; high risk/low awareness; low risk/high awareness; and low risk/low awareness overall; the working and middle classes were then compared in each region. In Figures 4 and 5, the $\mathrm{X}$ and $\mathrm{Y}$ reference lines have been drawn in at the overall average for risk likelihood and for awareness.

Overall, the regions at highest flood risk include Wales, Anglia, and the Thames regions (see Figure 4). However, a comparison of the flood awareness within those regions shows that while flood awareness overall is high in the Thames region, it is low in Anglia and Wales.

Figure 4 Overall flood risk and flood awareness in 2007-8

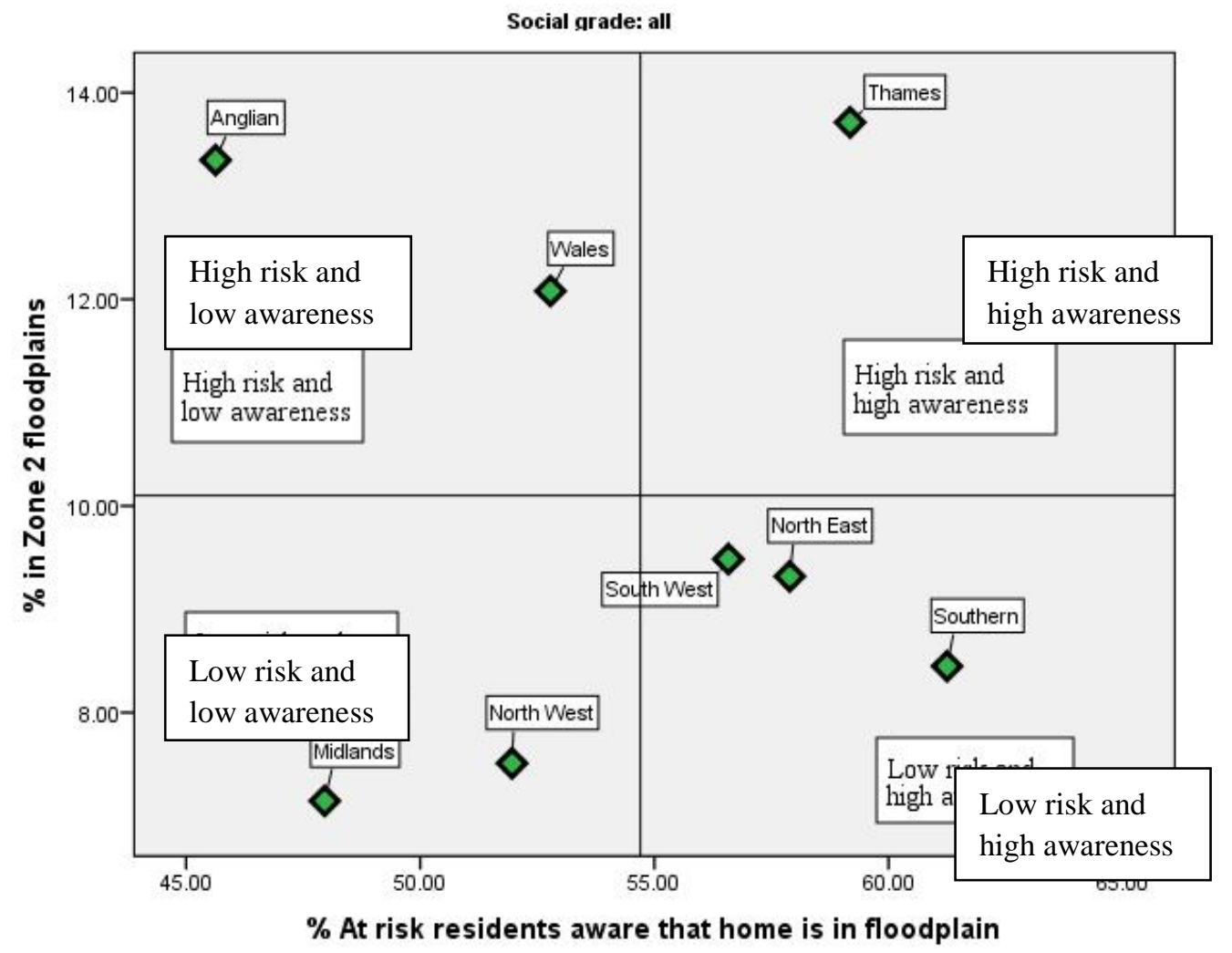

Source: author’s analysis of Ipsos MORI (2008); Census 2001(ONS, 2001)

\section{[B] Class differences, flood risk, and risk awareness}

This analysis also explores class differences. Figure 5 shows that it is predominately the working classes in Wales and the Thames and North East regions that experience high flood risk associated with low awareness of risk. The exception is seen in the Anglian region, where the middle and working classes share low awareness, although the working classes experience the highest flood risk.

To facilitate comparison across class differences in Figure 5, connecting lines link the classes of each region. The more vertical a line is, the more equal the level of awareness across the classes; the more horizontal a line is, the more equal the flood risk exposure. In addition, the shorter the line, the more equal awareness and/or risk. In other words, Figure 5 is a visualization of the regional inequalities in the etic flood risk and emic flood awareness. 
It reveals whether the flood risk of a location or the perception of one's safety is more equal or unequal between the middle and working classes in each region.

Figure 5 Visualization of inequalities between flood risks and flood awareness in 2007-8

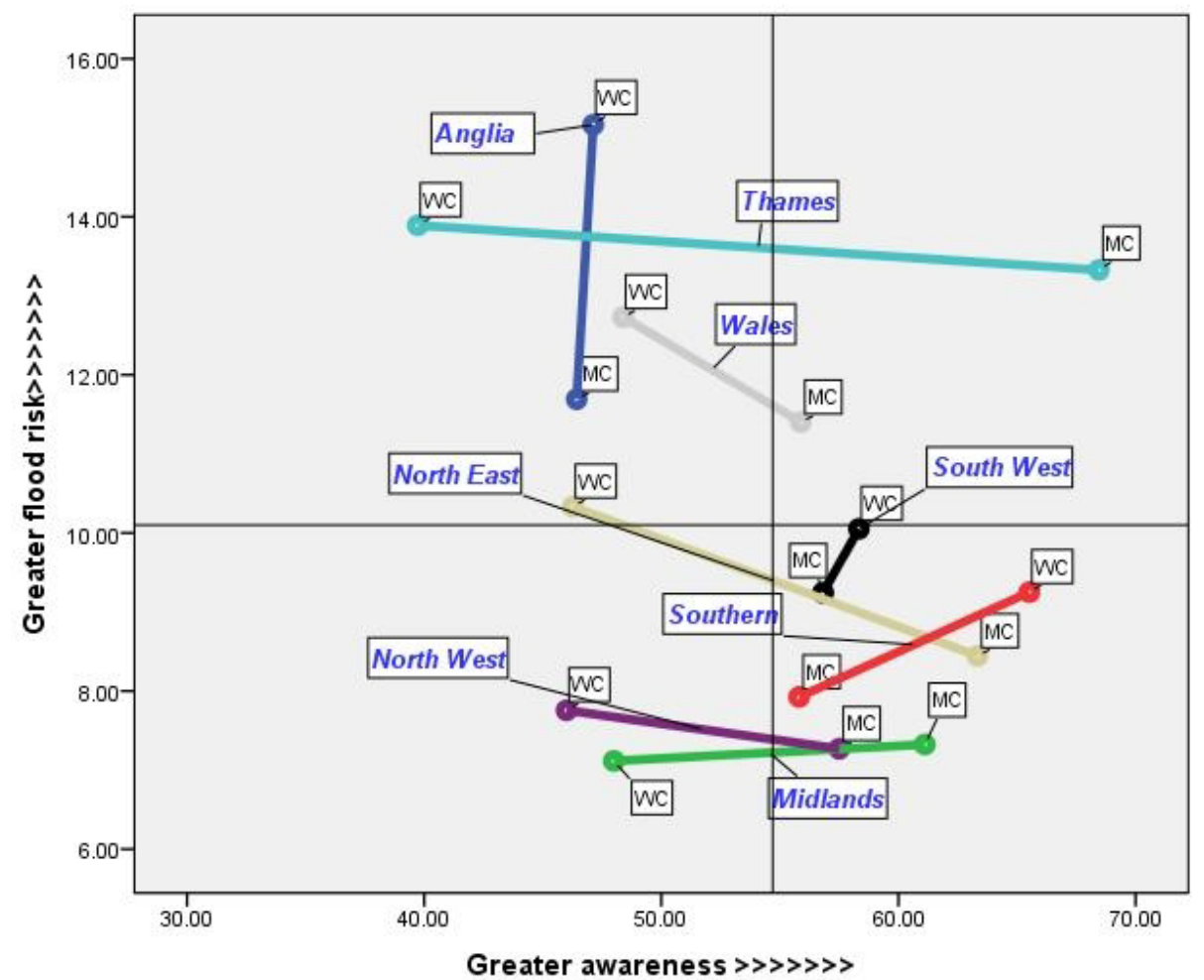

Notes: $\mathrm{MC}=$ middle class; $\mathrm{WC}=$ working class.

Source: author's analysis of Ipsos MORI (2008); Census 2001(ONS, 2001)

The longest line separates the working and middle classes in the Thames region, which exhibits the greatest differences in perception, although both groups are equally at flood risk. In contrast, the perception of risk in the Anglian region is equally low across the classes, although inequality is seen in the likelihood of living within the flood-risk zone, which is higher for the working classes. In Wales, the North West, and the Midlands, the levels of flood risk within regions are similar; however, in each case, the working classes are less aware of their risk than the middle classes, though not significantly. In the Southern and the South West regions, both classes are in the same quadrant in Figure 5; the working classes are more aware of their risk, which is lower than average in both regions. Perhaps the most notable difference is seen in the North East, where the two groups are in diametrically opposite quadrants; the working classes are at high risk with low awareness and the middle classes experience low risk and high awareness.

All in all, the inequalities of flood risk vary across regions. In the Thames region, the perception of risk is a concern; in Anglia, inequality characterizes the likelihood of exposure to that risk; and in the North East, inequalities lie within the etic flood risk, the likelihood of living within the floodplains, and the emic perception of that risk.

\section{[A] Discussion}

Clearly, there are large differences in both flood risk likelihood and flood awareness in England and Wales. These differences are often class-dependent. In all areas except the 
Midlands, the working classes are more likely to reside in the floodplains; the greatest inequality is seen in the North East and in the Anglian region. However, these inequalities may not have arisen through any positive discrimination; they should be an area for further research.

Yet, despite uncertainly regarding the origins of these inequalities, there is much research to show that they are inequitable. Such research has shown that it is often the most deprived who are least able to cope in a flood event and these results should be of concern to policymakers and flood emergency managers developing flood warning policy (Cutter, 2003; Cutter and Emrich, 2006; Cutter et al., 2003 Fordham, 1998; 1999; Tapsell et al., 2002; Wisner et al., 2004). However, these are all measures of objective, etic risk defined by the flood maps. It is equally important to explore and understand the perception of people who live in those areas, and the emic, subjective risk.

This research has explored that subjective risk quantitatively using a secondary analysis of survey data collected in 2007-8. Findings show that flood awareness in some areas, especially the Anglian and the Midlands regions, was much lower than average; however, there were no significant class differences in these regions. It was in the Thames area, an area of overall higher-than-average awareness, that the greatest class differences were seen. Here, the working classes are significantly less aware than their middle-class neighbours, despite living at equal flood risk. Yet it was the working classes living in the North East who bear the greatest burden. Not only are they living in riskier places, but they are significantly less aware of their risk than their middle-class counterparts. While it has been shown that previous flood experience may partially explain differences in flood awareness in the North East, it does not explain the class differences in flood awareness seen in the Thames areas.

Further research is thus needed, not only to establish the origins of inequalities in hazard exposure, but also to determine what impact other factors may have on hazard awareness. To explore the origins of inequalities in hazard exposure, a historical longitudinal analysis of population migration patterns into and out of flood prone areas (especially coastal immigration) should be conducted. This can then be extended to predict future hazard exposure following the predicted changes due to climate change. It would also be useful to establish what proportion of social housing is built in flood-risk areas. The results may suggest that the inequalities demonstrated in this paper are not only inequitable but also unjust, in that the greatest impact would be felt by those least able to choose where they live.

At the regional level, some areas are especially in need of further research. The Thames region is not only the area at greatest flood risk in England and Wales, but it also exhibits disproportionately lower levels of flood awareness among the most deprived, as measured by social class. Of course, it also contains the national capital, London, and experiences the greatest dynamic population turnover. To explain not only lower levels of awareness, but also regional differences in awareness, more research, particularly qualitative research, is needed to assess the resident populations' everyday understanding of their exposure to flood risk. Such research can serve to inform appropriate action in and prior to any emergency situation.

In addition, it is important to consider regional differences in the light of recent predictions of increased flooding due to climate change, not only globally (Milly et al., 2002), but also in the UK (UKCIP, 2009). Predictions for the UK have announced that there will be wetter, milder winters and more frequent storms, especially in the south. Coupled with this increased flood risk in the Southern region are the predictions of immigrant inflow into the UK. Migration statistics show that net migration is increasing steadily (ONS, n.d.). About half a million people immigrate to the UK each year, yet about one-third of a million emigrate, resulting in a net influx of about 200,000 per year. This increase largely concerns London and the South East. Given that migrant population are likely to increase over the next decades, coupled with evidence that climate change will probably have an impact on the areas that 
have the highest inflow of migrants (London and the South East), it is likely that these communities will be most affected; these concerns should be high on any research agenda.

This study has demonstrated that area differences in awareness are complex and that there is great regional variation, not only in awareness but also flood risk. Yet while all areas (except the Midlands) show a disproportionate increase in flood risk affecting the working and inactive classes, there are some areas where this is especially pronounced, such as the North East. In addition, perhaps because of this inequality, the working classes in the North East are significantly less likely to be aware of the flood risk; indeed, they shoulder a double risk burden.

\section{[A] Correspondence}

Jane L. Fielding, Department of Sociology, University of Surrey, Guildford GU2 7XH, United Kingdom.

E-mail: j.fielding@surrey.ac.uk.

\section{[A] References}

Bottero, W. (2004) . 'Class Identities and the identity of class'. Sociology. 38(5). pp. 9851003.

Bracken, I. and D. Martin (1989) 'The generation of spatial population distributions from census centroid data'. Environment and Planning A. 21(4). pp. 537-43.

Buckle, P., G. Marsh, and S. Smale (2000) 'New approaches to assessing vulnerability and resilience'. Australian Emergency Management Journal. 15(2). pp. 8-15.

Burningham, K., J. Fielding, and D. Thrush (2008) “"It'll never happen to me”: understanding public awareness of local flood risk’. Disasters. 32(2). pp. 216-38.

CDU (Census Dissemination Unit) (n.d.) ‘Casweb’. http://casweb.mimas.ac.uk. (Accessed 5 February 2010).

Chandola, T. (2000) 'Social class differences in mortality using the new UK National Statistics Socio-Economic Classification’. Social Science \& Medicine. 50 (5). Pp.641-649.

Chatterton, J., C.Viavattene, Jo. Morris, E. Penning-Rowsell and S. Tapsell (2010) The Cost of the 2007 Floods in England. Environment Agency R\&D Report SCHO1109BRJA-E-P. Environment Agency, Bristol.

Cutter, S.L. (2003) 'The vulnerability of science and the science of vulnerability'. Annals of the Association of American Geographers. 93(1). pp. 1-12.

Cutter, S.L., B.J. Boruff, and W.L. Shirley (2003) 'Social vulnerability to environmental hazards’. Source Social Science Quarterly. 84(2). pp. 242-61.

Cutter, S.L. and C.T. Emrich (2006) 'Moral hazard, social catastrophe: the changing face of vulnerability along the hurricane coasts'. Annals of the American Academy of Political and Social Science. 604(1). pp. 102-12.

Cutter, S.L. C. Emrich, J. J. Webb and D. Morath (2009) Social Vulnerability to Climate Variability Hazards: A Review of the Literature-Final Report to Oxfam America. Columbia, SC: Hazards and Vulnerability Research Institute, University of South Carolina. http://adapt.oxfamamerica.org/resources/Literature_Review.pdf (accessed 30th August 2011).

Devine, F. and Savage, M. (2000) 'Conclusions: Renewing class analysis'. In R. Crompton, F. Devine, M. Savage, and J. Scott (eds) Renewing class analysis. Blackwell, Oxford. pp. 184-199.

EA (Environment Agency) (2001) Achieving Environmental Equality. Annual general meeting debate. 5 September 2000. Bristol: EA. 
EA (n.d.a) 'Flood'.. http://www.environment-

agency.gov.uk/homeandleisure/floods/default.aspx. (accessed February 2010).

EA (n.d.b) 'Over 40 per cent of people in flood areas unaware they are at risk'. http://www.environment-agency.gov.uk/news/100382.aspx. (accessed August 2010).

Enarson, E. and M. Fordham (2001) 'Lines that divide, ties that bind: race, class and gender in women's flood recovery in the US and UK'. Australian Journal of Emergency Management. 15(4). pp. 43-52.

EPA (United States Environmental Protection Agency) (n.d.) 'Environmental justice'. http://www.epa.gov/environmentaljustice (accessed August 2011).

Erikson, R. (1984) 'Social class of men, women and families'. Sociology. 18 (4). pp. 500514.

Erikson, R. and J.H. Goldthorpe (1992) The Constant Flux, Clarendon, Oxford.

ESRC (Economic and Social Research Council) (2001) Environmental Justice: Rights and Means to a Healthy Environment for All. ESRC Global Environmental Change Programme Special Briefing No. 7. University of Sussex, Brighton.

Fielding, J. (2007) 'Environmental injustice or just the lie of the land: an investigation of the socio-economic class of those at risk from flooding in England and Wales'. Sociological Research Online. 12(4). http://www.socresonline.org.uk/12/4/4.html.

Fielding, J. and K. Burningham (2005) 'Environmental inequality and flood hazard'. Local Environment. 10(4). pp. 379-95.

Fielding, J., K. Gray, K. Burningham, and D.Thrush (2005) Flood Warning for Vulnerable

Groups: Secondary Analysis of Flood Data. R\&D Report W5C-018/2. Environment Agency,

Bristol.

Fielding, J., K. Burningham, D. Thrush, and R. Catt, (2007) Public Response to Flood Warning. R\&D Report SC02011. Environment Agency. Bristol.

Fordham, M. (1998) 'Making women visible in disasters: problematising the private domain'. Disasters. 22(2). pp. 126-43.

Fordham, M. (1999) 'The intersection of gender and social class in disaster: balancing resilience and vulnerability’. International Journal of Mass Emergencies and Disasters. 17(1). pp. 1537.

Foresight (2004) Future Flooding Volume 1: Future Risks and their Drivers. Department for Business, Innovation \& Skills. London.

Fothergill, A. and L. Peek (2004) 'Poverty and disasters in the United States: a review of recent sociological findings’. Natural Hazards. 32(1). pp. 89-110.

Green, C.H., S.M. Tunstall, and M.H. Fordham (1991) 'The risks from flooding: which risks and whose perception?’ Disasters. 15(3). pp. 227-36.

Hugo, G. (1996) 'Environmental concerns and international migration'. International Migration Review. 30(1). pp. 105-31.

Ipsos MORI (2008) Flood Awareness Campaign Tracking Survey 2007-2008. Ipsos MORI, London.

Leake, J. (2009) 'Climate change may push migrants to cooler Britain'. Sunday Times. 8 November. http://www.timesonline.co.uk/tol/news/environment/article6908002.ece. (accessed August 2011).

Marshall, G., A. Swift and S. Roberts (1997) Against the Odds; Social class and social justice in industrial societies. Oxford University Press, Oxford.

Martin, D. (1989) 'Mapping population data from zone centroid locations'. Transactions of the Institute of British Geographers New Series. 14(1). pp. 90-7.

Martin, D. and I. Bracken (1999) 1981 and 1991 Population Surface Models: A Guide. CCS605. Manchester: Census Dissemination Unit, University of Manchester. 
Milly, P.C., et al. (2002) 'Increasing risk of great floods in a changing climate'. Nature. 415. pp. 514-7.

National Archives (n.d.) Indices of Deprivation 2004 [online]. Available from: http://webarchive.nationalarchives.gov.uk/+/http://www.communities.gov.uk/archived/gen eral-content/communities/indicesofdeprivation/216309/ (Accessed August 2011)

ODPM (Office of the Deputy Prime Minister) (2004) The Planning Response to Climate Change: Advice on Better Practice. Her Majesty’s Stationery Office, London.

ONS (Office for National Statistics) (n.d.) 'Long-term international migration (LTIM) tables: 1991-latest’. http://www.statistics.gov.uk/STATBASE/Product.asp?vlnk=15053.

ONS (Office for National Statistics) (2001) 2001 Census: Standard Area Statistics (England and Wales) [computer file]. ESRC/JISC Census Programme, Census Dissemination Unit, Mimas (University of Manchester). Available at: http://www.census.ac.uk/ (accessed August 2011).

Pitt, M. (2008) Pitt Review: Learning Lessons from the 2007 Floods. Cabinet Office, London.

Raleigh, C., L. Jordan, and I. Salehyan (2008) Assessing the Impact of Climate Change on Migration and Conflict. Paper prepared for the World Bank Seminar on Exploring the Social Dimensions of Climate Change. World Bank, Washington, DC.

Rose, D., O'Reilly, K. and Martin, D. (1997) 'ESRC Review of Government Social Classification'. Population Trends. 89. pp 49-89.

Scambler, P \& Higgs, P. (2001) 'The dog that didn't bark': taking class seriously in the health inequalities debate. Social Science \& Medicine. 52 (1). pp. 157-159.

Spiers, J. (2000) 'New perspectives on vulnerability using emic and etic approaches'. Journal of Advanced Nursing. 31(3). pp. 715-21.

Surface Builder software (n.d) Available at : http://www.public.geog.soton.ac.uk/users/martindj/davehome/software.htm (accessed August 2011).

Talih, M. and R.D. Fricker (2002) 'Effects of neighbourhood demographic shifts on findings of environmental injustice: a New York City case-study'. Journal of the Royal Statistical Society: Series A (Statistics in Society). 165(2). pp. 375-97.

Tapsell, S.M., E.C. Penning-Rowsell, S.M. Tunstall, and T.L. Wilson (2002) 'Vulnerability to flooding: health and social dimensions'. Philosophical Transactions-Royal Society of London Series A: Mathematical and Physical Sciences. 360(1796). pp. 1511-25.

UKCIP (United Kingdom Climate Projections) (2009) 'Climate Change Projections Report'. Available at: http://ukclimateprojections.defra.gov.uk/content/view/944/500/. (accessed August 2011).

Walker, G., G. Mitchell, J. Fairburn and G. Smith (2003) Environmental Quality and Social Deprivation. R\&D Technical Report E2-067/1/TR. Environment Agency, Bristol.

Walker, G., K. Burningham, J. Fielding, G. Smith, D. Thrush, and H. Fay (2006) Addressing Environmental Inequalities: Flood Risk. Science Report SC020061/SR1. Environment Agency, Bristol.

Wisner, B., P. Blaikie, T. Cannon, and I. Davis (2004) At Risk: Natural Hazards, People's Vulnerability and Disasters. $2^{\text {nd }}$ edn. Routledge, London and New York. 